\title{
Radiation-induced angiosarcoma of the omentum diagnosed by laparoscopy: A case report
}

\author{
HARUKO KUNITOMI $^{1}$, KOUJI BANNO ${ }^{1}$, HAYATO ISEKI $^{1}$, ASAKO SERA ${ }^{1}$, \\ AZUMI MIYAUCHI ${ }^{1}$, YUSUKE KOBAYASHI ${ }^{1}$, SHIGENORI HAYASHI ${ }^{1}$, EIICHIRO TOMINAGA ${ }^{1}$, \\ AYA SASAKI $^{2}$, MIHO KAWAIDA ${ }^{2}$, KAORI KAMEYAMA ${ }^{2}$ and DAISUKE AOKI ${ }^{1}$ \\ ${ }^{1}$ Department of Obstetrics and Gynecology, and ${ }^{2}$ Division of Diagnostic Pathology, \\ Keio University School of Medicine, Tokyo 160-8582, Japan
}

Received July 13, 2017; Accepted November 17, 2017

DOI: $10.3892 / \mathrm{mco} .2017 .1513$

\begin{abstract}
Angiosarcoma is a rare malignant tumor with an aggressive clinical course and a poor prognosis. Intraperitoneal angiosarcoma, especially originating from the omentum, is extremely rare. We report a case of radiation-induced angiosarcoma of the omentum that arose in a 38-year-old female seven years after concurrent chemoradiotherapy for cervical cancer. The primary tumor was unknown until diagnostic laparoscopy revealed an unresectable omental mass. Pathological examination revealed high-grade malignant cells positive for endothelial markers. Although the small number of cases limits the consensus on optimal therapy for advanced angiosarcoma, the patient was managed successfully by taxane-based chemotherapy, leading to complete response and consequent complete cytoreductive surgery. Our report is the fifth case of radiation-induced angiosarcoma of the omentum, and all have developed after treatment for gynecologic cancer. Although very rare, this complication should be considered after radiation therapy in cancer treatment, particularly given the increasing importance of this therapy.
\end{abstract}

\section{Introduction}

Angiosarcoma is a rare aggressive malignant tumor of vascular endothelial origin (1) that mainly causes cutaneous lesions. Angiosarcoma originating in the omentum is extremely rare, with only few previous reported cases (2-5). Here, we report a case of angiosarcoma of the greater omentum arising in a prior radiation field 7 years after concurrent chemoradiotherapy for cervical cancer.

Correspondence to: Dr Kouji Banno, Department of Obstetrics and Gynecology, Keio University School of Medicine, 35 Shinanomachi, Shinjuku-ku, Tokyo 160-8582, Japan

E-mail: kbanno@z7.keio.jp

Key words: angiosarcoma, laparoscopy, omentum, radiation-induced neoplasms, chemotherapy

\section{Case report}

A 38-year-old female visited our outpatient clinic complaining of abdominal pain and distension. She had a history of concurrent chemoradiotherapy for squamous cell carcinoma of the cervix 7 years ago, which had led to complete clinical remission. The prior treatment included whole pelvic irradiation (50.4 Gy/28Fr), intracavitary brachytherapy (18 Gy/3Fr), and three courses of systemic cisplatin administration. She had no other relevant medical history and familial history.

On presentation, the patient was generally ill and had a markedly distended abdomen. The pelvic examination was normal and pelvic MRI scan showed an atrophic but otherwise normal uterus and bilateral adnexa (Fig. 1A). Positron emission tomography CT scans revealed an omental mass with prominent FDG uptake, massive bloody ascites, and signs suspicious of peritonitis carcinomatosis (Fig. 1B). Gastroscopy and colonoscopy findings were unremarkable. Cervical and endometrial cytology were negative for malignancy. Ascites cytology obtained by paracentesis revealed solitary, scattered multinucleated giant cells with prominent nucleoli (Fig. 1C,d); however, the findings did not prove malignancy due to the small number of suspicious cells. CA125 was elevated $(237 \mathrm{mIU} / \mathrm{ml})$, while other tumor markers (SCC, CEA and CA19-9) were negative.

Intra-abdominal cancer of unknown primary origin was suspected and diagnostic laparoscopy was performed. Laparoscopic examination revealed intensive peritoneal inflammation, massive bloody ascites (Fig. 2A) and a congested greater omental mass of $15 \mathrm{~cm}$ in diameter (Fig. 2B). This mass reached the splenic flexure and had invaded close to the splenic hilum. There was a small papillary lesion on the surface of the left ovary, which was suspicious for dissemination (Fig. 2C). The right adnexa (Fig. 2D) and the uterus were atrophic and adhered to the peritoneal wall with no apparent lesion. Biopsy of the omental mass, bilateral partial oophorectomy and right salpingectomy were performed. A frozen section of the omental mass was diagnosed as poorly differentiated malignant tumor. The operation time was $65 \mathrm{~min}$ and blood loss was $1,150 \mathrm{ml}$.

Microscopically, the tumors were composed of high-grade malignant cells with frequent mitosis, forming irregular 
Table I. Radiation-induced angiosarcoma arising in the omentum.

\begin{tabular}{|c|c|c|c|c|c|c|c|c|}
\hline Authors (year) & Age & Sex & $\begin{array}{l}\text { Previous } \\
\text { malignancy }\end{array}$ & $\begin{array}{l}\text { Radiation } \\
\text { to onset }\end{array}$ & $\begin{array}{c}\text { Intra- } \\
\text { peritoneal } \\
\text { hemorrhage }\end{array}$ & Treatment & Prognosis & (Refs.) \\
\hline Westenberg et al (1989) & 59 & $\mathrm{~F}$ & Cervical cancer & 8 years & + & Unknown & Unknown & (7) \\
\hline Sakemi et al (2011) & 74 & $\mathrm{~F}$ & Cervical cancer & 5 years & + & Palliative & 34 days died & (8) \\
\hline $\begin{array}{l}\text { Chudecka-Glaz et al } \\
\text { (2014) }\end{array}$ & 55 & $\mathrm{~F}$ & Ovarian cancer & 20 years & + & $\begin{array}{l}\text { Chemotherapy, } \\
\text { Surgery }\end{array}$ & $\begin{array}{l}16 \text { months } \\
\text { died }\end{array}$ & (9) \\
\hline Narayanan et al (2015) & 77 & $\mathrm{~F}$ & Cervical cancer & Unknown & + & $\begin{array}{l}\text { Surgery, } \\
\text { palliative care }\end{array}$ & Unknown & (10) \\
\hline Present case & 38 & $\mathrm{~F}$ & Cervical cancer & 7 years & + & $\begin{array}{l}\text { Chemotherapy, } \\
\text { surgery }\end{array}$ & $\begin{array}{l}\text { Currently } \\
\text { disease } \\
\text { Free } \\
\text { (8 months) }\end{array}$ & \\
\hline
\end{tabular}

F, female.
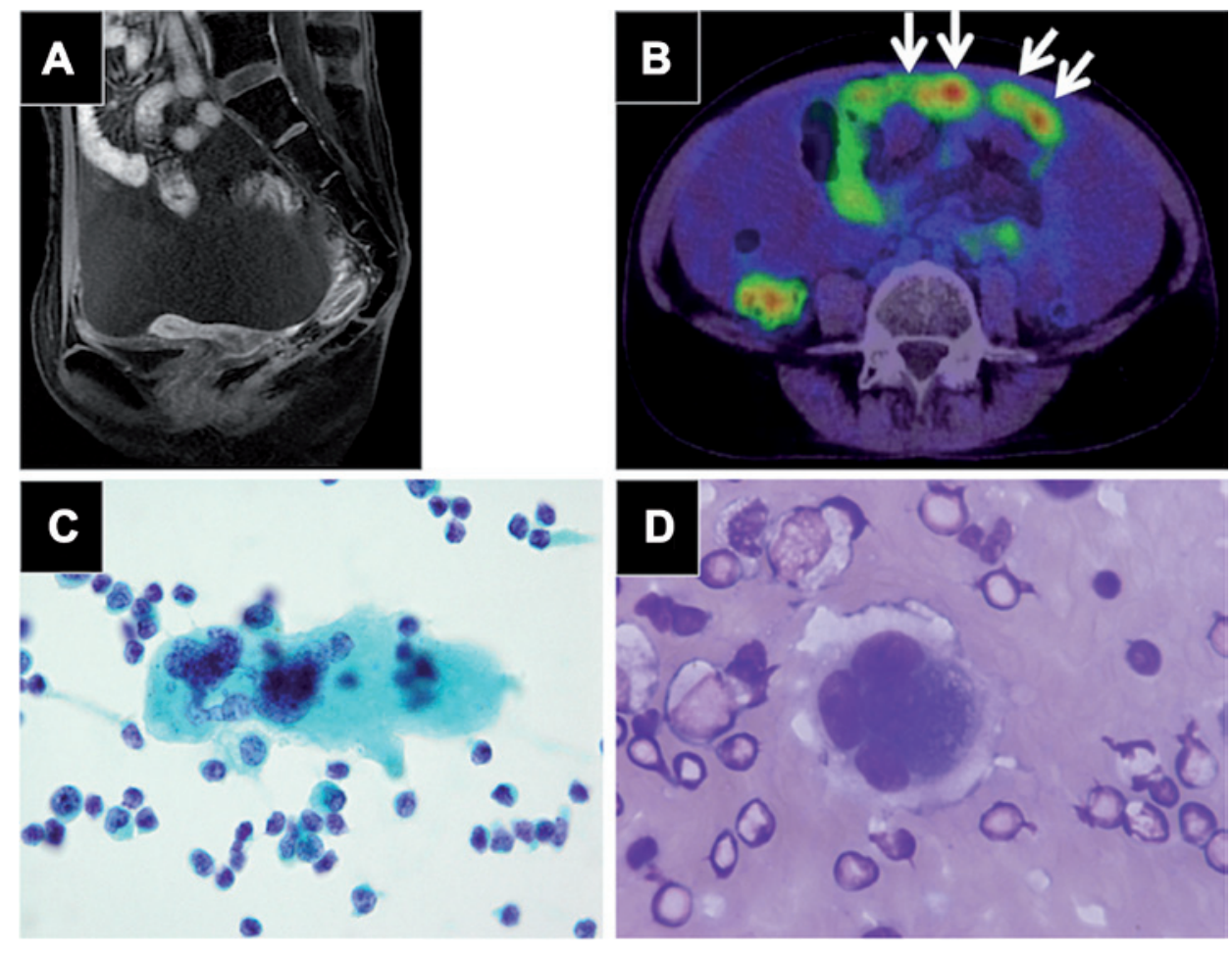

Figure 1. Preoperative evaluation. (A) Pelvic MRI showing a normal uterus. (B) PET/CT revealed massive bloody ascites, an omental mass (arrows), and a diffusely distended small intestine suggestive of peritonitis carcinomatosis. (C) Papanicolaou stain and (D) Giemsa stain of the ascites revealed solitary multinucleated giant tumor cells with prominent nucleoli. Magnification, x100.

anastomosing vascular channels containing erythrocytes (Fig. 3A). The same findings were present in the left Fallopian tube, indicating dissemination. Immunohistochemistry revealed positive staining for endothelial markers CD31 (Fig. 3B), CD34 (Fig. 3C) and ERG. The lymphatic endothelial marker D2-40 (Fig. 3D) was positive, whereas cytokeratin (AE1/AE3), estrogen receptor, progesterone receptor and WT-1 were negative. The cell block technique for ascites revealed a few cells positive for CD34 (Fig. 3E) and ERG (Fig. 3F).
The diagnostic criteria for radiation-induced sarcoma include pathologically proven sarcoma developing in a prior radiation field, normal findings prior to radiotherapy, and at least a three-year period after radiotherapy (6). Fulfilling the above criteria, the clinical and pathological findings led to the diagnosis of radiation-induced angiosarcoma of the greater omentum. The advanced tumor was unresectable; therefore, weekly paclitaxel $\left(100 \mathrm{mg} / \mathrm{m}^{2}\right.$ on days $1,8,15,22,29,36$ in a 7-week cycle, as approved in Japan) was started 11 days after surgery, which lead to complete response after six courses, and 

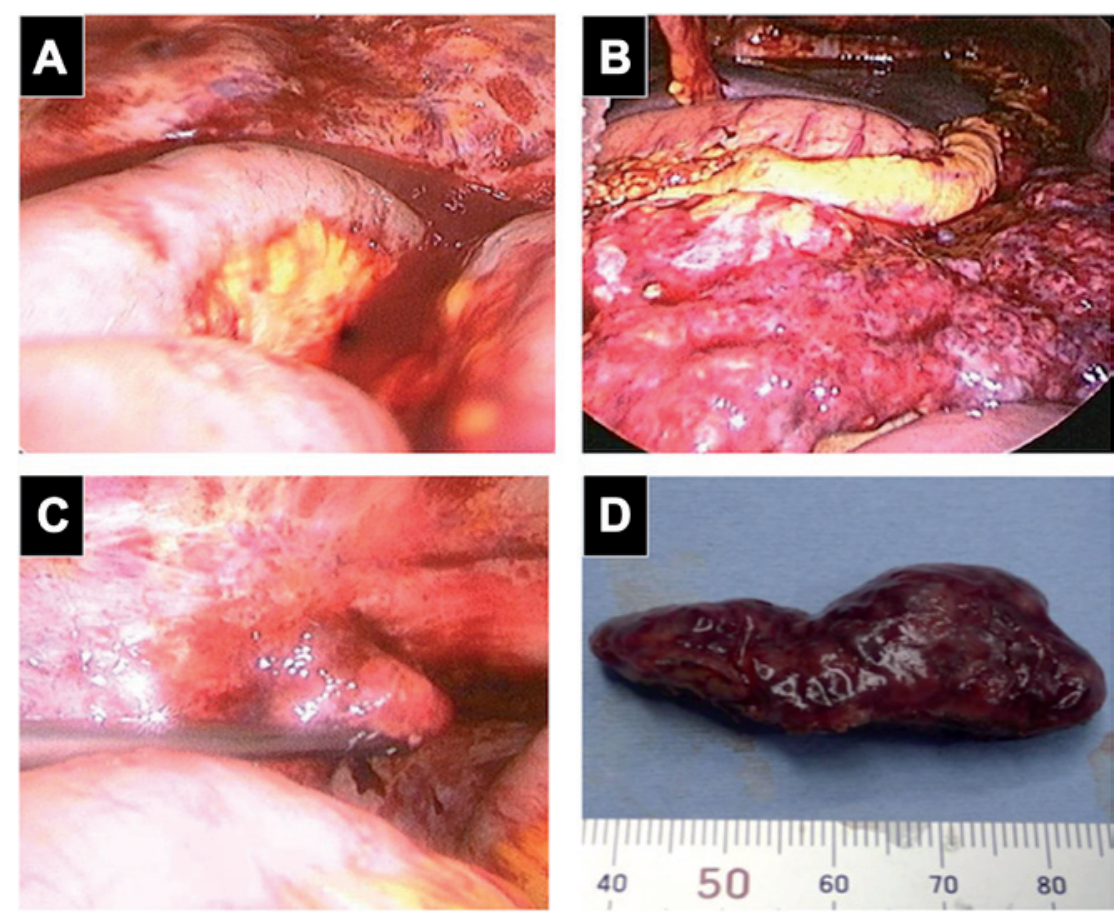

Figure 2. Laparoscopic findings. (A) Massive bloody ascites and peritoneal inflammation were observed. (B) A congested omental mass invaded close to the splenic hilum. (C) A small papillary lesion (arrow) is seen on the surface of the left Fallopian tube. (D) Macroscopic findings of the biopsied omental mass.
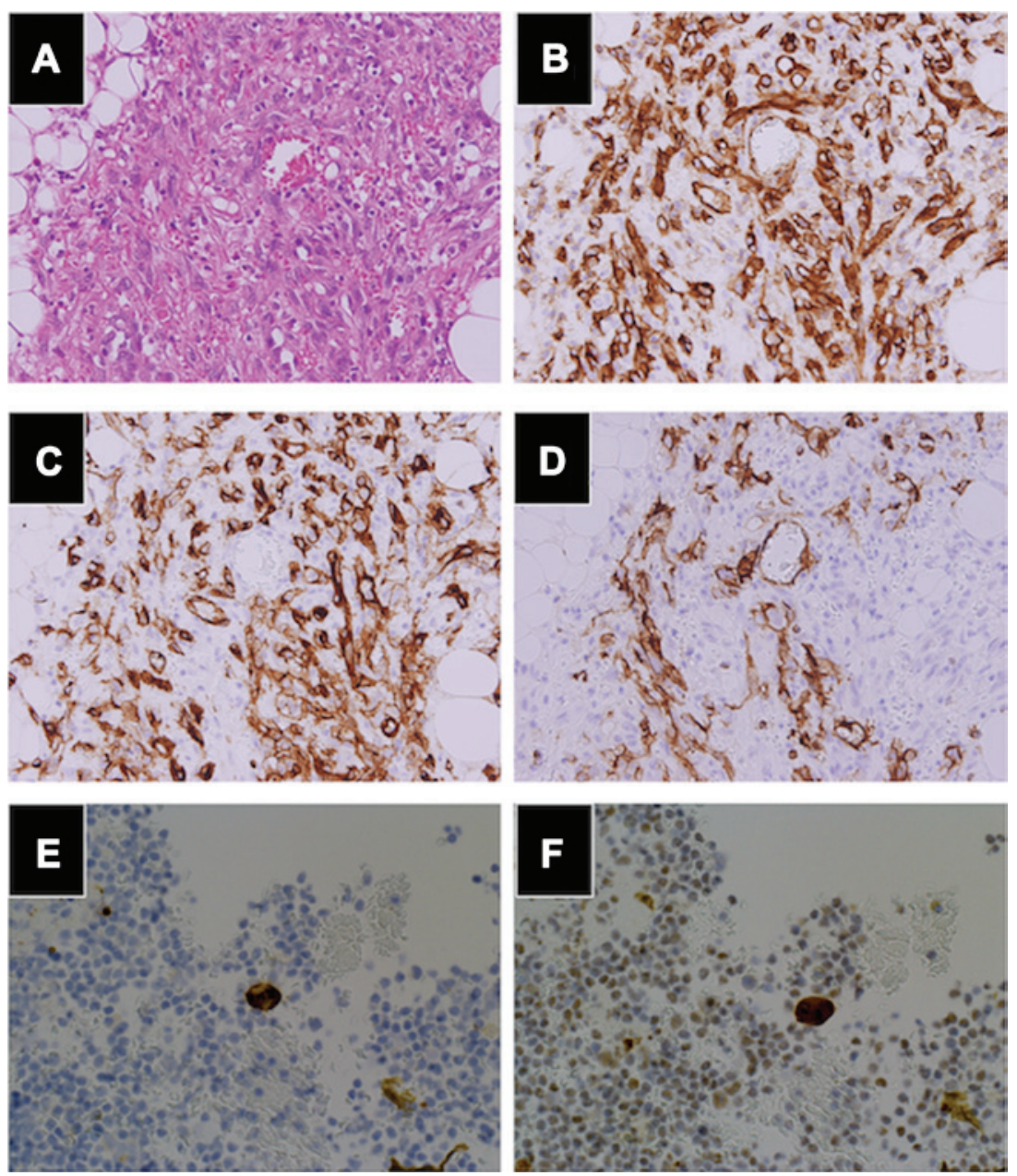

Figure 3. Histopathological findings. (A) H\&E stains of the omental mass showed high-grade malignant cells with frequent mitosis, forming irregular anastomosing vascular channels. Immunohistochemistry was positive for (B) CD31, (C) CD34 and partially positive for (D) D2-40, while pan-keratin was grossly negative. The cell block method was used for immunohistochemical investigation of ascites, and showed a small number of cells positive for (E) CD34 and (F) ERG. (A-C) Magnification, x20; (E-F) Magnification, x40. 
complete cytoreductive surgery was performed consequently. Currently, the patient remains disease free 3 months post surgery.

\section{Discussion}

Angiosarcoma is a rare, aggressive malignant tumor of vascular endothelial origin (1) that comprises approximately $2 \%$ of soft-tissue sarcomas. The most common site is the head and neck in elderly patients, whereas cases of intraperitoneal origin are extremely rare. The prognosis of angiosarcoma is generally poor, $19-43.9 \%$ of cases present with advanced disease $(7,8)$ and the median survival period is $7-12$ months $(7,8)$.

Secondary soft tissue sarcoma is an uncommon but important adverse event following radiation therapy. As the importance of radiation therapy in cancer treatment has grown over the years, the number of recognized radiation-induced sarcomas is also growing. In a study of 4,884 adult patients with soft tissue sarcoma, $2.5 \%$ were diagnosed as radiation-induced, of which $15 \%$ were patents with angiosarcoma (9). Radiation-induced angiosarcoma accounts for $3-12.2 \%$ of all angiosarcomas (7), and among patients who received radiotherapy for primary cancer, the standardized incidence ratio of angiosarcoma was 6.0 (95\% CI 2.7-11), compared to patients who received other treatment (10). Compared to other subtypes, radiation-induced angiosarcoma has a particularly poor prognosis; even local lesions recur in $87.5 \%$ of cases, and the median survival period is 7-8 months (7).

The patient described herein developed angiosarcoma in a prior radiation field 7 years after cervical cancer treatment, and in this respect this is a typical case of radiation-induced angiosarcoma. However, most radiation-induced angiosarcomas occur in the skin of patients after radiation treatment for breast cancer (7). Only four previous cases of angiosarcoma originating in the greater omentum have been reported, all of which were consequences of radiation therapy for gynecologic cancer (2-5) (Table I). All cases presented with advanced disease, which were complicated with massive hemorrhagic ascites and peritoneal dissemination. While the cases receiving palliative care described the rapidly progressing character of the disease $(3,5)$, Chudecha-Glaz et al reported the achievement of partial response by platinum-based chemotherapy, which lead to cytoreductive surgery and control of the disease at least temporarily (4). Swiftly making the diagnosis and enabling chemotherapy administration seems to be the key in controling the disease.

Due to the low prevalence and lack of specific markers, prompt diagnosis of intraperitoneal angiosarcoma is a challenge. Our current experience suggests the clinical usefulness of diagnostic laparoscopy. The importance of diagnostic laparoscopy is emerging for intraperitoneal cancer of unknown primary origin, where minimal invasiveness is required for high-risk patients. This method permits precise evaluation of the cancer origin, determination of the feasibility of complete cytoreduction, and conversion to laparotomy as needed. Further, for an unresectable tumor, diagnostic laparoscopy allows sufficient biopsy for pathological examination with permissive complications (11). With use of diagnostic laparoscopy, we were able to initiate systemic treatment only 11 days postoperatively in the current case.
For advanced stage angiosarcoma, systemic cytotoxic chemotherapy is the treatment of choice. Due to the lack of clinical trials for angiosarcoma patients, anthracycline- and ifosfamide-based regimens have been considered as first line chemotherapy following the results of clinical trials for other soft tissue sarcomas $(12,13)$. However, recently, few studies have shown the efficacy of taxane-based therapy for angiosarcoma. In a retrospective study in 32 patients with angiosarcoma who received triweekly or weekly paclitaxel, the EORTC soft tissue and bone group found a response rate of $62 \%$ and a median time to progression of 7.6 months (12). In the ANGIOTAX phase II trial (14), weekly paclitaxel $\left(80 \mathrm{mg} / \mathrm{m}^{2}\right.$ on days 1,8 , and 15 of a 4-week cycle) was administered to 30 patients with unresectable angiosarcoma. The response rate was $19 \%$ after 6 courses, but the regimen achieved a relatively high non-progression rate (75\% at 3 months and $24 \%$ at 6 months), and the median progression free survival (PFS) and overall survival (OS) were 4 and 8 months, respectively. Taking these studies into account, the NCCN guidelines currently recommend weekly paclitaxel as first line chemotherapy for angiosarcoma; however, further clinical trials are needed to optimize standard therapy.

Herein, we have reported a case of radiation-induced angiosarcoma originating in the greater omentum in a 38-year-old female. Radiation-induced angiosarcoma following treatment of gynecologic cancer is clearly a rare complication, but should be considered, especially with the increasing importance of radiation therapy for treatment of invasive cervical cancer.

\section{Acknowledgements}

Written informed consent was obtained from the patient for the publication of this case report, and ethics approval was given from the ethical committee of our institute (approval no. 20070081). We thank the patient for allowing discussion of her case with the academic community.

\section{References}

1. Young RJ, Brown NJ, Reed MW, Hughes D and Woll PJ: Angiosarcoma. Lancet Oncol 11: 983-991, 2010.

2. Westenberg AH, Wiggers T, Henzen-Logmans SC, Verweij J, Meerwaldt JA and van Geel AN: Post-irradiation angiosarcoma of the greater omentum. Eur J Surg Oncol 15: 175-178, 1989.

3. Sakemi M, Sakemi R, Harada M, So S, Uchiyama D, Morimitsu Y, Kakiuchi S, Ishihara Y, Kubo Y, Matsugaki S, et al: A case of postirradiation angiosarcoma of the greater omentum with hemorrhage. Clin J Gastroenterol 4: 302-306, 2011.

4. Chudecka-Głaz A, Menkiszak J, Kuźniak S, Lewandowska M, Burak M and Walecka A: A rare case of peritoneal disseminated angiosarcoma 20 years after ovarian cancer diagnosis. Gynecol Obstet Invest 77: 68-72, 2014.

5. Narayanan S, Parker M, Shayo J, Zheng M, Matulewicz T and Parker G: The Impact of Radiation on an Unusual Case of Omental Epithelioid Angiosarcoma. Case Rep Surg 2015: 849059, 2015.

6. Arlen M, Higinbotham NL, Huvos AG, Marcove RC, Miller T and Shah IC: Radiation-induced sarcoma of bone. Cancer 28: 1087-1099, 1971.

7. Abraham JA, Hornicek FJ, Kaufman AM, Harmon DC, Springfield DS, Raskin KA, Mankin HJ,Kirsch DG, Rosenberg AE, Nielsen GP, et al: Treatment and outcome of 82 patients with angiosarcoma. Ann Surg Oncol 14: 1953-1967, 2007.

8. Fayette J, Martin E, Piperno-Neumann S, Le Cesne A, Robert C, Bonvalot $\mathrm{S}$, Ranchère $\mathrm{D}$, Pouillart $\mathrm{P}$, Coindre $\mathrm{JM}$ and Blay JY: Angiosarcomas, a heterogeneous group of sarcomas with specific behavior depending on primary site: A retrospective study of 161 cases. Ann Oncol 18: 2030-2036, 2007. 
9. Cha C, Antonescu CR, Quan ML, Maru S and Brennan MF: Long-term results with resection of radiation-induced soft tissue sarcomas. Ann Surg 239: 903-910, 2004.

10. Virtanen A, Pukkala E and Auvinen A: Angiosarcoma after radiotherapy: A cohort study of 332,163 Finnish cancer patients Br J Cancer 97: 115-117, 2007.

11. Marmor RA, Kelly KJ, Lowy AM and Baumgartner JM: Laparoscopy is safe and accurate to evaluate peritoneal surface metastasis prior to cytoreductive surgery. Ann Surg Oncol 23: 1461-1467, 2016.

12. Schlemmer M, Reichardt P, Verweij J, Hartmann JT, Judson I, Thyss A, Hogendoorn PC, Marreaud S, Van Glabbeke M and Blay JY: Paclitaxel in patients with advanced angiosarcomas of soft tissue: A retrospective study of the EORTC soft tissue and bone sarcoma group. Eur J Cancer 44: 2433-2436, 2008.
13. Agulnik M, Yarber JL, Okuno SH, von Mehren M, Jovanovic BD, Brockstein BE, Evens AM and Benjamin RS: An open-label, multicenter, phase II study of bevacizumab for the treatment of angiosarcoma and epithelioid hemangioendotheliomas. Ann Oncol 24: 257-263, 2013.

14. Penel N, Bui BN, Bay JO, Cupissol D, Ray-Coquard I, Piperno-Neumann S, Kerbrat P, Fournier C, Taieb S, Jimenez M, et al: Phase II trial of weekly paclitaxel for unresectable angiosarcoma: The ANGIOTAX Study. J Clin Oncol 26: 5269-5274, 2008.

(i) $\mathrm{T}$ This work is licensed under a Creative Commons Attribution-NonCommercial-NoDerivatives 4.0 International (CC BY-NC-ND 4.0) License. 